\title{
Is There an Association Between Pituitary Adenomas and Autonomic Cephalgia?
}

\author{
Şükran Kaygısız ${ }^{1}$, Özlem Coşkun², Serap Üçler ${ }^{3}$, Levent Ertuğrul İnan ${ }^{4}$, Burç Esra Şahin ${ }^{5}$ \\ ${ }^{1}$ Department of Neurology, Ordu Research and Training Hospital, Turkey \\ ${ }^{2}$ Department of Neurology, Faculty of Medicine, Kırıkkale University, Turkey \\ ${ }^{3}$ Department of Neurology, Faculty of Medicine, Health Sciences University, Turkey \\ ${ }^{4}$ Department of Neurology, Faculty of Medicine, Bozok University, Turkey \\ ${ }^{5}$ Department of Neurology, Faculty of Medicine, Ahi Evran University, Turkey \\ Received: 16 April 2019, Accepted: 20 July 2019, Published online: 31 December 2019 \\ (C) Ordu University Institute of Health Sciences, Turkey, 2019
}

\begin{abstract}
Objective: Trigeminal autonomic cephalalgias (TACs) are a group of primary headache syndromes. Although hemicrania continua (HC)is not included among the TACs according to the International Classification of Headache Disorders (ICHD-II), it also shows autonomic symptoms. In the literature, some authors suggest that TACs can be related with pituitary lesions. In this study, we have compared the pituitary lesions observed in the TAC, HC and migraine-type headache patients

Methods The cranial magnetic resonance images (MRI) of the patients with TAC, HC and migraine without aura (MWOA) unaccompanied by autonomic symptoms were retrospectively evaluated. The $33 \mathrm{TAC}$ and $\mathrm{HC}$ patients were compared with the 30 migraine without aura (MWOA) patients.

Results: The mean age of the TAC and HC patients was $43.36 \pm 10.72$ years, whereas the mean age of the MWOA patients was $39.0 \pm 6.92$ years. No statistically significant difference in terms of age was observed between the groups ( $>>0.05)$. The MRI of the TACs and HC patients indicated that $62.5 \%$ (n:20) were normal, while $12.5 \%$ (n:4) had pituitary microadenomas, $6.3 \%$ (n:2) had macroadenomas, $12.5 \%$ (n:4) had suspected pituitary microadenomas, and $6.3 \%(\mathrm{n}: 2)$ had suspected heterogeneity. The MRI results of the MWOA patients were normal in $46.7 \%$ (n:14), whereas $23.3 \%$ (n:7) had pituitary microadenomas, $23.3 \%$ (n:7) had suspected pituitary microadenomas, and 6. $2 \%$ (n:2) had suspected pituitary heterogeneity. No statistically significant difference was observed between both groups $(p>0.05)$.

Conclusion: In this study, no correlation was observed between the TACs, HC and pituitary abnormalities. In conclusion, the use of pituitary MRI has not been supported as a routine method in patients with this type of headache
\end{abstract}

Key words: Hypophysis, Headache, Pituitary Hormones

Suggested Citation: Kaygisiz S, Coskun O, Ucler S, Inan LE, Sahin BE. Is There an Association Between Pituitary Adenomas and Autonomic Cephalgia? Middle Black Sea Journal of Health Science, 2019; 5(2):252-257

\section{Address for correspondence/reprints:}

DOI: $10.19127 / \mathrm{mbsjohs} .554125$

Şükran Kaygısız

Telephone number: +90 (452) 2252525

E-mail: skrnkygsz@windowslive.com 


\section{Introduction}

Headaches are among the most commonly observed neurological symptoms and they constitute an important healthcare issue (Inan, 2011). Among the patients who present to neurology clinics, $2 / 3$ complain from headaches and $1 / 3$ present solely due to headaches (Baykan et al., 2011). According to the diagnostic criteria revised by the IHS in 2004, headaches have been classified in two main groups as primary and secondary headaches (Olesen, 2004). Primary headaches are more commonly observed. On the other hand, trigeminal autonomic cephalalgia, hemicrania continua (TOC-HC) belong to a less frequently observed group of primary headache syndromes characterized by unilateral headaches. As the name suggests, these headaches are associated with ipsilateral cranial autonomic findings and include cluster headaches, paroxysmal hemicranias, and short-lasting unilateral neuralgiform headache with unilateral conjunctival injection and tearing (SUNCT). Also, hemicrania continua is among the other primary headaches accompanied by autonomic symptoms (Saip, 2011). These autonomic symptoms can be observed with considerable frequency in case of headaches such as migraines (Uluduz, et al,2016)

The pathophysiology of autonomic headaches is yet to be cleared. In these types of headaches, secondary causes should be ruled out (Saip, 2011).

The secondary causes in the literature include a significant number of pathologies associated with the pituitary gland. However, among the cases reported in the literature, atypical features generally accompany headaches and therefore pituitary anomalies may be observed more frequently in these patients (Lai, 2009), (Elisabetta, 2009). The association of autonomic symptoms with pituitary adenomas has been studied before. The aim of the present study is to compare the pituitary magnetic rezonans image (MRI) anomalies of the patients with migraines unaccompanied by autonomic symptoms and the pituitary MRI anomalies in the patients with trigeminal autonomic headache and hemicrania continua. We also aim to investigate the requirement for pituitary MRI in the patients with headaches with autonomic symptoms and without atypical features.

\section{Methods}

Patients followed up by the Headache Outpatient Clinic of the Ministry of Health, Ankara Training and Research Hospital, Department of Neurology and diagnosed with TOC-HC and migraine without aura unaccompanied by autonomic symptoms based on the diagnostic criteria published by the International Headache Society (IHS) in 2004 (Baykan, 2011). were enrolled in the study. The study included 33 patients with TOC-HC, and 33 patients with migraine without aura unaccompanied by autonomic symptoms, of which the complete patient files could be retrieved.

The diagnoses of all the patients were reviewed based on the headache study forms. Their physical and neurological examinations were conducted by the same neurologist and the results were observed to be normal in all the patients. Patients with anomalies were excluded from the study. Patients with migraine or TOC-HC whose files contained brain MRI and pituitary MRI examinations were included in our study. The pituitary hormone test results of the patients in which the pituitary hormones were tested were noted. Brain MRI and pituitary MRI examinations were evaluated with specialist radiology and neurology.

The approval of the local ethics committee of Ministry of Health, Ankara Training and Research Hospital was obtained (2011) and the study was planned according to the latest version of the Helsinki Declaration and the Good Clinical Practices Guidelines.

\section{Statistical Analysis}

The study data were analyzed using the SPSS for Windows 11.5 software packages. The normality of the distribution of the continuous variables was investigated with the help of the Shapiro Wilk test. The descriptive statistics were indicated in mean \pm standard deviation for the continuous variables and in patient number and percentage (\%) for the nominal variables. The groups were compared using the suitable test from amongst the Chi-square test, Student's t-test or Fisher's Exact Test.

Statistical significance of the results was based on a value of $\mathrm{p}<0.05$.

\section{Results}

For the purpose of our study, 40 patients with TOC-HCand 33 patients with migraine without aura unaccompanied by autonomic symptoms were enrolled in our study. However, since the initial statistical analysis pointed to an age difference, 7 patients from the TOC-HC group and 3 patients from the migraine group were excluded from the study and the statistical analysis was repeated. Consequently, our study included 33 patients diagnosed with TOC-HC and 33 patients with migraine without aura unaccompanied by 
autonomic symptoms. The mean age of the patient group with TACs was $43.36 \pm 10.72$, while the mean age of the patient group was 39. $0 \pm 6.92$. There was no statistically significant difference between both groups ( $>00.05)$. Among the TOCHC patients, $45.5 \%(n=15)$ were male while $54.5 \%$ $(\mathrm{n}=18)$ were female. Among the migraine patients, $20 \% \quad(n=6)$ were male while $80 \% \quad(n=24)$ were female.

Among the patient group with TOC, $15.2 \%$ $(n=5)$ were followed up for episodic cluster headaches, 9.1\% $(n=3)$ for chronic cluster headaches, $6.1 \%(\mathrm{n}=2)$ for episodic paroxysmal hemicrania, 36.3\% $(n=12)$ for chronic paroxysmal hemicrania, 3\% $(n=1)$ for SUNCT, 27.3\% $(n=9)$ for hemicrania continua, and $3 \%(n=1)$ were followed up for stabbing headaches (Figure 1).

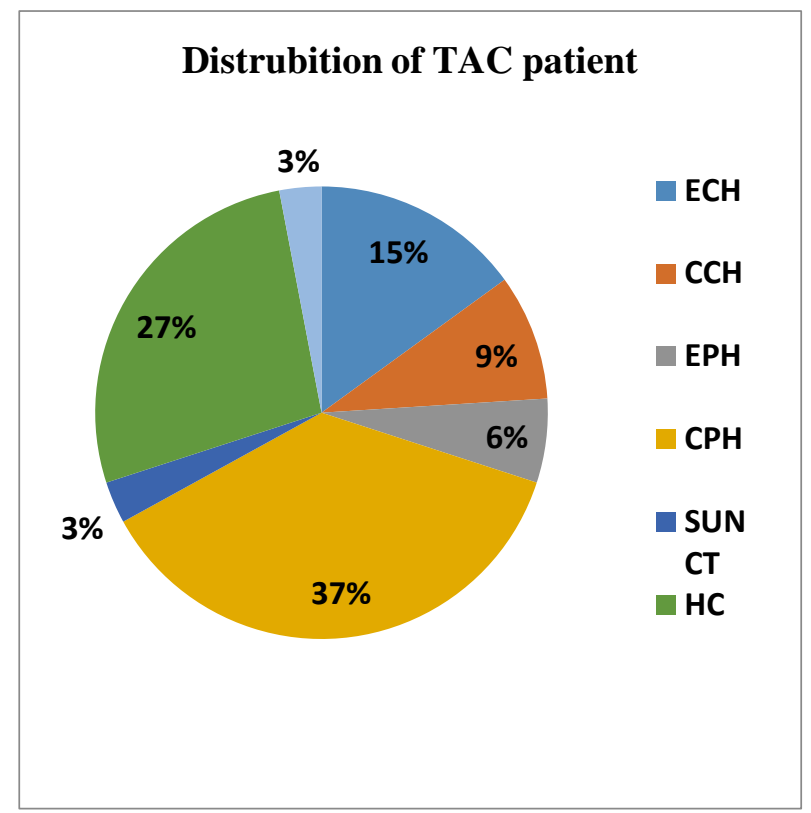

Figure 1. Distribution of TAC cases

The physical examination was normal in all the patients. No abnormalities were observed in the neurological examinations.

In the patient group with TOC-HC, 87. 9\% $(n=29)$ has unilateral headache which did not change sides, while this ratio was $26.7 \%$ in the group with migraine $(n=8)$. The difference between both groups was statistically significant $(p<0.05)$.

The autonomic symptoms of the patients with TOC and HC included conjunctival injection and tearing in $48.5 \%(n=16)$, nasal discharge and nasal obstruction in $24.2 \%(\mathrm{n}=8)$, conjunctival injection and tearing in $12.1 \%(\mathrm{n}=4)$, nasal obstruction and facial sweating in $6.1 \% \quad(n=2)$, conjunctival injection and nasal obstruction in $6.1 \% \quad(n=2)$, conjunctival injection and tearing and nasal discharge in $6.1 \%(\mathrm{n}=2)$ and sweating in the forehead and face in 3\% $(n=1)$ (Figure 2).

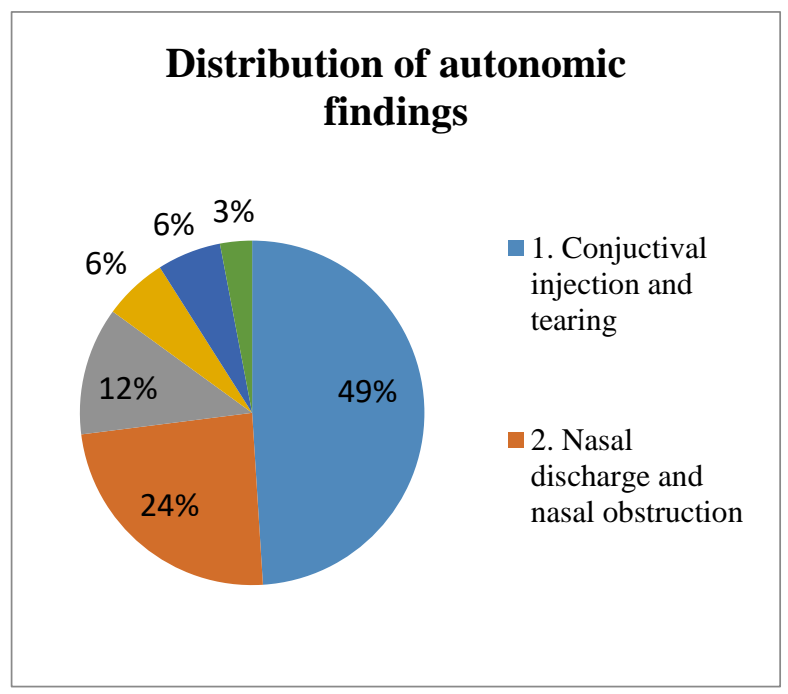

Figure 2. Distribution of autonomicfindings

Among the patients with TOC-HC, the pituitary MRI results were normal in $62.5 \%(n=20)$, while it revealed microadenomas in $12.5 \% \quad(n=4)$, macroadenomas in $6.3 \% \quad(n=2)$, suspected microadenomas in $12.5 \%(\mathrm{n}=4)$, and suspicious heterogeneity in the pituitary gland in $6.3 \%(\mathrm{n}=2)$. No cavernous sinus invasions were observed in any of the patients. The pituitary MRI of the patients with migraine were normal in $46.7(n=14)$, while it revealed microadenomas in $23.3 \%(\mathrm{n}=7)$, suspected microadenomas in $23.3 \%(\mathrm{n}=7)$, and suspicious heterogeneity in the pituitary gland in $\% 6,2(n=2)$. No statistically significant difference was observed between the TOC-HC and migraine patient groups in terms of the occurrence and distribution of pituitary lesions ( $\mathrm{p}>0.05)$ (Figure 3 ).

Among the 33 TOC-HC patients, 25 could be reached, while 30 of the migraine patients could be contacted. No statistically significant difference was observed regarding the FSH, LH, ACTH, GH, PRL values $(p>0.05)$. 


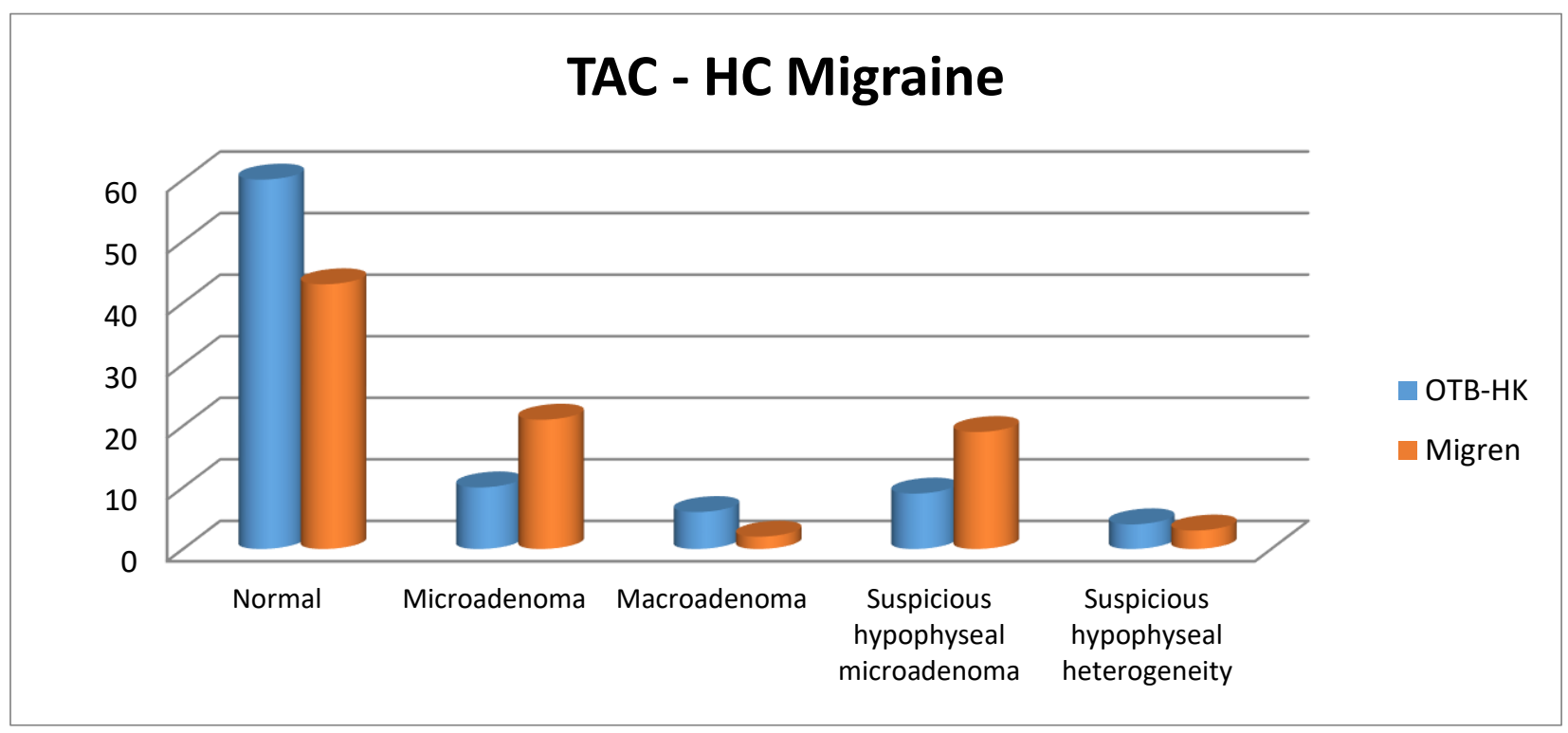

Figure 3. TAC- HC migraine

\section{Discussion}

TAC is a group of primary headache syndromes characterized by unilateral headaches and associated with ipsilateral cranial autonomic symptoms (Olesen, 2004). The most frequently observed type of TOC is cluster headache, while paroxysmal hemicrania and SUNCT are less frequently observed. Thee syndromes differ both in terms of the treatment response and the duration and frequency of the attack (Shuu- Jiun et al., 2009).

Hemicrania continua is among the very rarely observed primary headaches accompanied by autonomic symptoms (Olesen, 2004). While the male/female ratio in $\mathrm{HC}$ was previously reported as $1 / 5$, it has recently been reported as 1/2-3 (Matharu, 2007). In our patient group, this ratio was $1 / 2$, which was in line with the literature.

Among the patients with cluster headaches, 80$90 \%$ are episodic cluster headaches $(\mathrm{ECH})$ while 10 $-20 \%$ are chronic cluster headaches $(\mathrm{CCH})$. In our study, $62.5 \%$ were $\mathrm{ECH}$, which indicated a higher frequency than $\mathrm{CCH}$. The male/female ratio in cluster headaches was 2/1(Ozturk, 2011). In our patient group, all of the 8 cluster headache patients were male.

Paroxismal hemicrania is a type of TAC characterized by short attacks. While $80 \%$ of the cases are chronic paroxysmal hemicranias, 20\% have the episodic form (Levy et al. ,2005). In line with the literature, also in our study, $84.6 \%$ of the patients with paroxysmal hemicranias had $\mathrm{CCH}$, while $15.4 \%$ had ECH. Paroxysmal hemicrania is considered to be prevalent among females (Chinar et al., 2018). Also, in our patient group, it was more frequent among female patients, which was in line with the literature.

In another study by Wang et al. conducted in patients with pituitary adenomas, the association of headaches with the cranial autonomic symptoms were investigated and the frequency of macroadenoma and acromegaly was found to be higher in patients with cranial autonomic symptoms in comparison to those without cranial autonomic symptoms (Jacson et al,. 2009). These findings point out that a structural factor of pituitary adenomas may constitute a probable pathogenesis for headaches in patients with cranial autonomic symptoms. The diagnoses of the patients with autonomic symptoms were found as chronic migraine or probable chronic migraine in 56\%, hemicrania continua in $17 \%$, and cluster headache in $17 \%$ (Elisabetta, 2009). Unlike this study, in our study, we have investigated the association of pituitary adenomas in patients with autonomic symptoms. Similarly, macroadenomas were more frequently observed in patients with autonomic symptoms in our study, although the result did not reach statistical significance. Also, acromegaly was observed in 1 patient in the group with autonomic symptoms.

Explanations regarding the relationship between headache and pituitary tumors include tension in the dura mater and invasion of the allogenic structures resulting from cavernous sinus invasion. Two studies focusing on the association between the tumor size and cavernous sinus invasion did not find any relationship between these factors and showed that solely physical factors cannot adequately 
explain headaches (Matharu, 2007). (Wang et al,. 2009).

Tumor size or invasion is not a satisfactory explanation for cephalgia (Ozturk, 2011). In line with the literature, no relationship was observed between headache and the size and invasion of the tumor in our study.

In a study in the literature where the characteristics of pituitary adenomas and headaches were investigated, the most commonly observed types of tumour were non-functional adenoma with 46. 9\%, prolactinoma with $18 \%$, and $\mathrm{ACTH}-$ producing adenoma with $17 \%$ (Abe T, et al. 1998). In another study conducted on patients with symptomatic TOC, 8 out of the 24 patients with chronic headache $(33 \%)$ had pituitary lesions, where 7 had functional adenomas and 1 had a nonfunctional adenoma. Among the 3 patients with paroxysmal headaches, 2 (67\%) had functional adenoma; 7 (70\%) out of the 10 SUNCT patients were associated with pituitary tumours, while 5 had functional and 2 had non-functional adenomas (Lai, 2009). In our study, except for 1 patient in the TOC$\mathrm{HC}$ group h-who had a hormone-producing adenoma, all the adenomas observed in this group and the groups of migraine patients were nonfunctional.

It is strongly suggested that the onset of the pituitary tumor headache has a hereditary biochemical - neuroendocrine background (Abe et al., 1998). In some patients with acromegalyassociated headache, somatostatin analogues such as octreotide may act as an instant pain-relief. The same condition is observed with dopamine agonists in patients with prolactinoma. However, more severe headaches have also been reported during these treatments (Wang et al, 2009). (Jacson et al., 2009).

In our study, only one patient was hormonally active and had acromegaly. In this patient, octreotide treatment led to an improvement in the headaches. Our study did not demonstrate a statistically significant relationship between headache and neuroendocrine factors.

\section{Limitations}

This is an observational, single-institution study, which had a relatively small sample size and was thus subject to various unaccounted confounders inherent in such an analysis.

\section{Conclusion}

In this study, we have investigated both the structural and hormonal role of pituitary lesions in the pathophysiology of autonomic symptoms. Our comparison between patients with TOC-HC and those with migraine without aura unaccompanied by autonomic symptoms did not demonstrate a statistically significant difference in terms of the association with pituitary lesions. These results render both the structural and hormonal effects of pituitary adenomas in the pathophysiology of autonomic symptoms doubtful. Further studies are required for clarification.

Ethics Committee Approval: Ethics committee approval was received for this study from 2012 Clinical Research Ethics Committee of Ankara education Ethics committee.

Peer-review: Externally peer-reviewed.

Author Contributions: Concept - ŞK, E İ, Design Ö Ç, Supervision Ş K, Materials - B E Ş, Data Collection and/or Processing - ŞK Analysis and/or Interpretation S Ü, Literature Review -Ş K, Writing - ÖÇ, Critical Review - Ş K.

Conflict of Interest: No conflict of interest was declared by the authors.

Financial Disclosure: The authors declared that this study has /hasn't received no financial support.

\section{References}

Abe T, Matsumoto K, Kuwazawa J, Kuwazawa J, Toyoda I, Sasaki K .Headache associated with pituitary adenomas. Headache 1998;38:782 - 86. Baykan B, Idrisoğlu HA. Headache .Oge AE, Baykan B, editor. Headache. İstanbul: Neurology Second edition. Nobel Medical Bookstores; 2011. P.373-94.

Chinar O, AnishB. Paroxysmal Hemicrania.Ann Indian Acad Neurol. 2018; 21:16-S22.

Dora B. New Horizons in Neurology.Inan L, editor. Other Trigeminal Autonomic Cephalgias.

Ankara: First edition; Gunes Medical Bookstores; 2011.p.97-114.

Elisabetta C, Manjit S. M. Symptomatic Trigeminal Autonomic Cephalalgias. The Neurologist.2009; 15: $305-312$.

Inan LE. New Horizons in Neurology.İnan L E, editor. General Approach to Headache Patient. Ankara: First edition; Gunes Medical Bookstores; 2011.p.1-13. 
Jacson A. G, Joao Paulo Cavalcante de Almeida, Lucas Alverne Freitas de Albuquerque, Michele Schops, Erika Gomes, Tania Ferraz. Headache associated with pituitary tumors. J Headache Pain.2009;10: 15 - 20.

Levy MJ, Jager HR, Powell M, Matharu MS, Meeran K, Goadsby PJ. Pituitary volume and headache: size is not everything. Arch Neurol.2004; 61: 721 - 725.

Matharu M, Godsby P. Trigeminal autonomic cephalalgias: diagnosis and management. In: Silberstein S, Lipton R, Dodick D, eds. Wolff's Headache and Other Head Pain. 8th ed. New York, NY: Oxford University Press. 2007; 379 430

Olesen J. Headache Classification Committee of the International Headache Society.Classification of the Headache Disorders 2. Edition. Cephalagia.2004; 24; Sup.1: 1-156.

Ozturk V. New Horizons in Neurology. Inan LE, editor. Cluster headache. Ankara: First edition; Gunes Medical Bookstores; 2011.p.81-96.

Saip S. New Horizons in Neurology. Inan LE, editor. Classification of headache disorders. Ankara: First edition; Gunes Medical Bookstores; 2011.p.15-32.

Shuu- Jiun W, Chia-Wei H, Jong-Ling F, Jiing- Feng L, Chii-Min H. Cranial Autonomic Symptoms in Patients with Pituitary Adenoma Presenting with Headaches. Acta Neurologica Taiwanica. 2009;18: 104 - 112 .

Uluduz D, Ayta S, Cranial Autonomic Features in Migraine and $\mathrm{M}$ igrainous Features in Cluster Headache. Noro Psikiyatr Ars. 2016;3:220-224

Wang SJ, Hung CW, Fuh JL, Lirng JF, Hwu CM. Cranial autonomic symptoms in patients with pituitary adenoma presenting with headaches. Acta Neurol Taiwan.2009;18(2):104-12.

Williams G, Ball JA, Lawson RA, Joplin GF, Bloom SR, Maskill MR. Analgesic effect of somatostatin analogue (octreotide) in headache associated with pituitary tumours. BJM.1987; 295: 247 -248. 